\title{
Molecular drivers of mitochondrial membrane proliferation in response to cold acclimation in threespine stickleback
}

\author{
Kelly Keenan, Megan Hoffman, Kristin Dullen and Kristin M. O’Brien*† \\ University of Alaska Fairbanks, Institute of Arctic Biology, Fairbanks, AK, 99775 \\ † all authors contributed equally to this work \\ *corresponding author \\ University of Alaska Fairbanks \\ Institute of Arctic Biology, P.O. Box 757000, Fairbanks, AK 99775 \\ Ph: 907-474-5311 \\ Fax: 907-474-7666 \\ Email:kmobrien@alaska.edu
}




\section{Abstract}

2 Little is known about how the synthesis of mitochondrial phospholipids is integrated into

3 mitochondrial biogenesis in fish or mammals. Glycerol-3-phosphate acyltransferase

4 (GPAT; EC 2.3.1.15) catalyzes the addition of fatty acyl CoA to the $s n-1$ position of

5 glycerol-3-phosphate, in what is considered the rate-limiting step in phospholipid

6 biosynthesis. Previous studies have shown that mitochondrial volume density increases

7 in oxidative skeletal muscle but not liver of Gasterosteus aculeatus (threespine

8 stickleback) in response to cold acclimation. We hypothesized that maximal activity of

9 GPAT would increase in oxidative skeletal muscle but not liver during cold acclimation,

10 coinciding with mitochondrial biogenesis. GPAT activity was measured in liver and

11 oxidative skeletal (pectoral adductor) muscle of threespine stickleback acclimated to $8{ }^{\circ} \mathrm{C}$

12 or $20{ }^{\circ} \mathrm{C}$. In addition, mRNA levels of enzymes involved in phospholipid synthesis,

13 including cytidine diphosphodiacylglycerol synthase-1 (CDS1), CDS2, GPAT1, GPAT2

14 and 1-acylglycerol 3-phosphate acyltransferase-2 (AGPAT2) were quantified in liver and

15 pectoral muscle of stickleback harvested during cold acclimation. GPAT activity and

16 transcript levels of AGPAT2 increased in response to cold acclimation in pectoral muscle

17 but not liver. Transcript levels of GPAT1 increased in liver but not pectoral muscle.

18 Overall our results suggest that the activity of GPAT, and possibly AGPAT as well,

19 increase during cold acclimation and may contribute to mitochondrial phospholipid

20 biosynthesis required for mitochondrial biogenesis.

21 Key Words: mitochondrial biogenesis, cold acclimation, threespine stickleback,

22 membrane biosynthesis

Abbreviations: AGPAT, 1-acylglycerol 3-phosphate acyltransferase; CDP-DAG, cytidine diphosphodiacylglycerol; CDS, cytidine diphosphodiacylglycerol synthase; CL,cardiolipin; DAG, diacylglycerol; EF-1 $\alpha$; elongation factor-1 alpha; G3P, glycerol 3-phosphate; GPAT, glycerol 3-phosphate acyltransferase; LPA, lysophosphatidic acid; LPAAT, lysophosphatidic acid acyltransferase; mTOR, mechanistic target of rapamycin; mtDNA, mitochondrial DNA; NRF-1, nuclear respiratory factor 1; PA, phosphatidic acid; PC, phosphatidylcholine; PE, phosphatidylethanolamine; PI, phosphatidylinositol; PS, phosphatidylserine; PGC$1 \alpha$, peroxisome proliferator-activated receptor gamma coactivator 1-alpha; TAG, triacylglycerol; TFAM, mitochondrial transcription factor A 


\section{Introduction}

Mitochondrial density increases in response to cold acclimation in oxidative skeletal muscle of many cold-active teleosts, including goldfish, striped bass, zebrafish and stickleback (Egginton and Sidell, 1989; Johnston and Maitland, 1980; Orczewska et al., 2010; Tyler, 1984). Mitochondria are chimeric organelles, possessing proteins encoded in both the mitochondrial and nuclear genomes. Thus, mitochondrial biogenesis requires coordination of the two genomes to synthesize mitochondrial proteins and lipids, and to replicate the mitochondrial genome. In mammals, the co-transcriptional activator peroxisome proliferator-activated receptor gamma coactivator 1-alpha (PGC-1 $\alpha)$ is considered the master regulator of mitochondrial biogenesis. In addition to regulating the transcription of nuclear-encoded genes destined for mitochondria, it also transactivates the expression of mitochondrial transcription factor A (TFAM), which is then translated on cytosolic ribosomes and imported into the mitochondrion where it induces mitochondrial DNA (mtDNA) replication and transcription, leading to an increase in mtDNA and proteins (Scarpulla, 2008). Less is known about mitochondrial biogenesis in fishes but several studies suggest that nuclear respiratory factor-1 (NRF-1) and PGC-1 $\beta$, rather than PGC$1 \alpha$, orchestrate the process (Bremer et al., 2015; Bremer et al., 2012; Orczewska et al., 2010). While mammalian studies have clearly delineated how mtDNA is replicated and mitochondrial proteins are synthesized during mitochondrial biogenesis, the molecular drivers mediating the synthesis of mitochondrial phospholipids remain largely unknown (O'Brien and Mueller, 2010).

Glycerol-3-phosphate acyltransferase (GPAT) catalyzes the first, committed step in glycerolipid synthesis (Wendel et al., 2009). GPAT catalyzes the addition of fatty acyl coenzyme

44 A (CoA) to the $s n-1$ position of glycerol-3-phosphate (G3P), producing lysophosphatidic acid (LPA). Downstream of GPAT, 1-acylglycerol-3-phosphate acyltransferase (AGPAT) [or lysophosphatidic acid acyltransferase (LPAAT)] catalyzes the addition of fatty acyl CoA to the $s n-2$ position of LPA, producing phosphatidic acid (PA). PA is then hydrolyzed to form diacylglycerol (DAG). PA is the precursor for synthesizing phosphatidylinositol (PI), phosphatidylglycerol (PG) and cardiolipin (CL); DAG is the precursor for synthesizing the most abundant membrane phospholipids: phosphatidylcholine (PC), phosphatidylethanolamine (PE) and phosphatidylserine (PS) (Takeuchi and Reue, 2009). The synthesis of CL, an essential phospholipid associated with the complexes of the mitochondrial respiratory chain, is 
53 synthesized from PA by cytidine diphosphodiacylglycerol (CDP-DAG) synthase (CDS)

54 (Horvath and Daum, 2013; Ren et al., 2014). There are two isoforms of CDS and both are 55 localized to the endoplasmic reticulum (ER) (D'Souza et al., 2014). Recent studies suggest

56 Tam41, also a CDS but localized to the mitochondrion, may play a more prominent role in the 57 synthesis of CL than CDS1 or CDS2 (Tamura et al., 2013). There are four isoforms of GPAT, 58 localized to the outer mitochondrial membrane (GPAT 1 and 2) and the ER membrane (GPAT 3 59 and 4) (Bell and Coleman, 1980). AGPAT1 and AGPAT2 are localized to the ER and have been 60 well characterized, but as many as 11 isoforms have been reported in mammals (Takeuchi and 61 Reue, 2009). Recent studies have revealed the first linkages between the synthesis of 62 mitochondrial proteins and phospholipids. Knocking out PGC-1 $\alpha$ and PGC-1 $\beta$ in mice results in 63 altered mitochondrial morphology and a decrease in mRNA levels of CDS1 and levels of CL, PC 64 and PE in hearts (Lai et al., 2014). Overexpression of PGC-1 $\alpha$ in extensor digitorum longus 65 (EDL) muscle of mice alters phospholipid profiles, increasing content of 18:0/22:6 PC and 18:0/22:6 PE, similar to changes observed in response to exercise, and these changes are

67 prevented by knocking out PGC-1 $\alpha$ (Senoo et al., 2015). Transcript levels of GPAT1, GPAT3, and LPAAT2 (AGPAT2) also increased in EDL of PGC-1 $\alpha$ null mice, suggesting one more of

69 these enzymes may drive phospholipid remodeling, although principle component analysis did 70 not support this (Senoo et al., 2015).

To shed light on how mitochondrial membrane synthesis is stimulated during cold-

72 induced mitochondrial biogenesis in fish, we measured the maximal activity of GPAT in liver

73 and oxidative pectoral adductor muscle of threespine stickleback held at $20^{\circ} \mathrm{C}$ and cold-

74 acclimated to $8{ }^{\circ} \mathrm{C}$. Previous studies in our lab have shown that mitochondrial density increases

75 in pectoral adductor muscle but not liver in response to cold acclimation (Orczewska et al.,

76 2010). We anticipated that if GPAT drives increases in mitochondrial membrane biosynthesis,

77 GPAT activity would increase in oxidative muscle but not liver. Additionally, we measured 78 transcript abundance of key genes of the phospholipid biosynthetic pathway: CDS1, CDS2, 79 GPAT1, GPAT2 and AGPAT2.

\section{Materials and methods}


Threespine stickleback, Gasterosteus aculeatus were collected in 2013 from Kashwitna

83 Lake, $\mathrm{AK}\left(61^{\circ} 50^{\prime} \mathrm{N}, 150^{\circ} 00^{\prime} \mathrm{W} ; 13.1^{\circ} \mathrm{C}\right)$ using minnow traps. Fish were transported to the

84 University of Alaska Fairbanks, housed in environmental chambers, and maintained on a 10:14

$85 \mathrm{hr}$ light:dark cycle in aerated, filtered $114 \mathrm{~L}$ aquaria filled with $0.35 \%$ Instant Ocean in distilled

86 water. Animals were held at $20^{\circ} \mathrm{C}$ for 20 weeks then half of the animals $(\sim 60)$ were cold

87 acclimated by decreasing the temperature in the environmental chamber to $15{ }^{\circ} \mathrm{C}$ on day $1,10{ }^{\circ} \mathrm{C}$

88 on day 2 , and $8{ }^{\circ} \mathrm{C}$ on day 3 . Warm-acclimated fish were maintained at $20^{\circ} \mathrm{C}$ for the duration of

89 the experiment. Fish were held at $8{ }^{\circ} \mathrm{C}$ or $20^{\circ} \mathrm{C}$ for an additional 11 weeks for measuring GPAT

90 activity. For measuring transcript levels, fish from $8{ }^{\circ} \mathrm{C}$ and $20^{\circ} \mathrm{C}$ were harvested 1,4 , and 9

91 weeks after the start of cold acclimation. Animals were harvested prior to feeding at the same

92 time each morning. Fish were euthanized with an overdose of tricaine methanesulfonate (250

$93 \mathrm{mg} \mathrm{L}{ }^{-1}$; $\mathrm{pH}$ 7) followed by cervical cord transection for assaying GPAT activity, and flash frozen

94 in liquid nitrogen for measuring mRNA levels. All protocols were approved by the UAF

95 Institutional Animal Care and Use Committee (135490-2 and 135490-7).

96

97

98

99

100

101

102

103

104

105

106

107

108

109

110

111

\subsection{Maximal activity of GPAT (EC 2.3.1.15)}

Liver and oxidative pectoral adductor muscle were excised on an ice-cold stage. Tissues from two individuals were pooled and homogenized in 8 volumes of buffer $(10 \mathrm{mM}$ Tris- $\mathrm{HCl}$, $0.25 \mathrm{M}$ sucrose, $1 \mathrm{mM}$ EDTA, $1 \mathrm{mM}$ DTT; $\mathrm{pH} 7.4$ at $4{ }^{\circ} \mathrm{C}$ ) using a Tenbroeck homogenizer. Protein concentrations were determined using a Bradford assay with bovine serum albumin (BSA) as a standard (Bradford, 1976). Initial assays were carried out in a $500 \mu 1$ reaction mixture containing $40 \mathrm{mM}$ Tris- $\mathrm{HCl} \mathrm{pH} 7.5,2 \mathrm{mM} \mathrm{MgCl}_{2}, 2 \mathrm{mg} \mathrm{ml}^{-1} \mathrm{BSA}$ (essentially fatty acid-free), 2 $\mathrm{mM} \mathrm{KCN}, 100 \mu \mathrm{M}$ palmitoyl-CoA or palmitoleoyl-CoA, 0.1-10 mM G3P and $0.1 \mu \mathrm{Ci}\left[{ }^{14} \mathrm{C}\right]$ glycerol-3-phosphate (Perkin Elmer, Waltham MA, USA) (Vancura and Haldar, 1994).

Reactions were initiated by the addition of $150-400 \mu \mathrm{g}$ of protein. Maximal GPAT activity was linear for 20 minutes and proportional to the amount of protein added. These assays indicated that $5 \mathrm{mM} \mathrm{G3P}$ was sufficient to saturate the enzyme and activities were equivalent using either palmitoyl-CoA or palmitoleoyl-CoA as a substrate (data not shown). GPAT activity in warmand cold-acclimated stickleback was assayed at $14{ }^{\circ} \mathrm{C}$ in a $500 \mu 1$ reaction mixture containing 40 $\mathrm{mM}$ Tris- $\mathrm{HCl} \mathrm{pH}$ 7.5, $2 \mathrm{mM} \mathrm{MgCl}_{2}, 2 \mathrm{mg} \mathrm{ml}^{-1} \mathrm{BSA}$ (essentially fatty acid-free), $2 \mathrm{mM} \mathrm{KCN}$, $100 \mu \mathrm{M}$ palmitoleoyl-CoA, $5 \mathrm{mM}$ G3P, $0.1 \mu \mathrm{Ci}\left[{ }^{14} \mathrm{C}\right]$ glycerol-3-phosphate, and $400 \mu \mathrm{g}$ protein. 
112 Reactions were stopped after 20 minutes by the addition of $0.5 \mathrm{ml} \mathrm{H}_{2} \mathrm{O}$-saturated 1-butanol.

113 Samples were centrifuged at $12,100 \mathrm{~g}$ for 5 minutes at room temperature. A $200 \mu \mathrm{L}$ aliquot of

114 the butanol layer was added to $10 \mathrm{~mL}$ liquid scintillation fluid (Ecolite MP Biomedicals, LLC,

115 Solon, OH, USA). ${ }^{14} \mathrm{C}$ was counted using an LS 6500 multi-purpose scintillation counter

116 (Beckman Coulter, Fullerton CA, USA). Maximal GPAT activity was measured in triplicate in 117 warm- and cold-acclimated animals $(N=6)$. Background activity was measured in reaction

118 mixtures lacking palmitoleoyl-CoA and subtracted from activity in the presence of substrate.

119 Specific activity of GPAT was calculated as nmol G3P acylated per min per mg protein (nmol $\left.120 \mathrm{~min}^{-1} \mathrm{mg}^{-1}\right)$.

1212.3 Gene expression

RNA was isolated from 10-30 mg of pectoral adductor muscle and liver tissue from 6-8

123 individuals harvested at each time point during cold and warm acclimation (described above)

124 using the RNeasy Fibrous Tissue Mini-kit (Qiagen, Valencia, CA, USA) as described previously

125 (Orczewska et al., 2010). RNA levels were quantified by measuring the absorbance at $260 \mathrm{~nm}$

126 with a NanoDrop ${ }^{\circledR}(\mathrm{ND}-1000)$ spectrophotometer. RNA integrity was verified by mixing $2 \mu 1$

127 RNA with loading buffer (5\% glycerol, 0.04\% bromophenol blue, $0.1 \mathrm{mM}$ EDTA, pH 8.0) and

128 separating it on a $2 \%$ agarose gel. Total RNA was reverse transcribed to complementary DNA

129 (cDNA) using TaqMan ${ }^{\circledR}$ reverse transcription reagents (Applied Biosystems, Foster City, CA,

130 USA) as described previously (Orczewska et al., 2010). Briefly, cDNA was synthesized in a 10

$131 \mu \mathrm{l}$ reaction containing $5.5 \mathrm{mM} \mathrm{MgCl}_{2}, 2.5 \mu \mathrm{M}$ random hexamers, $2 \mathrm{mM}$ deoxynucleotides

132 (dNTPs), $4 \mathrm{U}$ of RNase inhibitor, $37.5 \mathrm{U}$ reverse transcriptase and $200 \mathrm{ng}$ RNA. Reactions were

133 performed using an iCycler (Bio-Rad Laboratories) programmed at $25^{\circ} \mathrm{C}$ for $10 \mathrm{~min}, 48{ }^{\circ} \mathrm{C}$ for

$13430 \mathrm{~min}$, and $95^{\circ} \mathrm{C}$ for $5 \mathrm{~min}$.

Transcript levels of CDS1, CDS2, GPAT1, GPAT2, and AGPAT2 were measured in

136 pectoral adductor muscle and liver tissue using quantitative real-time PCR (qRT-PCR) as

137 described previously (Orczewska et al., 2010). Briefly, gene-specific primers were designed

138 using sequence information obtained from Ensembl (www.ensembl.org) and the software Primer

139 Express (Applied Biosystems) with at least one primer from each pair spanning a splice site to

140 ensure that genomic DNA was not amplified (Table 1). Primers were synthesized commercially 
141 (Invitrogen, Carlsbad, CA, USA). Transcript levels were measured using an ABI 7900HT

142 sequence detection system (Applied Biosystems) in triplicate. $20 \mu \mathrm{L}$ reaction mixtures contained

$1435 \mathrm{ng}$ cDNA, $10 \mu \mathrm{L}$ Power SYBR ${ }^{\circledR}$ Green Master Mix (Applied Biosystems) and $0.3 \mu \mathrm{M}$ of each

144 forward and reverse primer, with the exception that only $1 \mathrm{ng}$ of cDNA was used to quantify

145 transcript levels of $18 \mathrm{~S}$. Optimal primer concentration was determined by measuring transcript

146 levels using $0.2 \mu \mathrm{M}, 0.3 \mu \mathrm{M}$ and $0.4 \mu \mathrm{M}$ of each forward and reverse primer. A dissociation

147 curve was analyzed for each reaction to ensure specificity of each primer set. Two controls were

148 used to identify and omit samples with contaminating genomic DNA. One control replaced the

149 cDNA template with an equal volume of Milli-Q $\mathrm{H}_{2} \mathrm{O}$. The second control was prepared for each

150 sample during cDNA synthesis by omitting reverse transcriptase. Reaction efficiency and

151 relative quantity of input RNA were determined using a standard curve for each gene prepared

152 by pooling samples from warm- and cold-acclimated animals. The expression of each target gene

153 was normalized to $18 \mathrm{~S}$ rRNA in liver tissue and elongation factor-1 alpha (EF-1 $\alpha)$ in oxidative

154 muscle; the expression of these genes was previously determined to remain constant in

155 threespine stickleback during warm and cold acclimation (Orczewska et al., 2010).

$156 \quad 2.4$ Statistical analyses

157 Significant differences in mRNA levels, and mass and length of individuals used for 158 measuring mRNA levels, were determined using a one-way ANOVA. Differences in GPAT 159 activity among cold- and warm-acclimated animals and between tissue types were determined

160 using a two-way ANOVA. ANOVAs were followed by a post-hoc Tukey's honestly significant

161 difference test. Data were normally distributed as determined by a Shapiro-Wilk test. Equal

162 variance was confirmed with Bartlett's test. A Student's t-test was used to determine significant

163 differences in mass and length between cold- and warm-acclimated animals used for measuring

164 GPAT activity. Data are presented as means \pm s.e.m. Level of significance was set at $P<0.05$.

165 Statistical tests were performed using Sigma Plot V 11.2 (Systat Software, San Jose, CA, USA)

166 and JMP7 (SAS, Cary, NC, USA).

\section{3. Results}


There was no significant difference in body length or mass between warm- and coldacclimated stickleback used for measuring maximal GPAT activity (Table 2) or mRNA levels.

171 (Table 3).

\subsection{GPAT activity in warm-and cold-acclimated stickleback}

173

174

175

176

177

There was a significant difference in GPAT activity between tissues $(F=148.03, P<$ $0.001)$ and between warm- and cold-acclimated stickleback $(F=17.997, P<0.001)$. Maximal activity of GPAT was 2.9-fold higher in pectoral muscle $\left(0.29 \pm 0.01 \mathrm{nmol} \mathrm{min}^{-1} \mathrm{mg}^{-1}\right.$ protein $)$ of cold-acclimated animals compared to those held at $20{ }^{\circ} \mathrm{C}\left(0.10 \pm 0.02 \mathrm{nmol} \mathrm{min}{ }^{-1} \mathrm{mg}^{-1}\right.$ protein; $^{\circ}$ $P<0.001$ ) (Fig. 1). There was no difference in GPAT activity in liver tissue between warm- and cold-acclimated individuals $(P=0.236)$. Maximal GPAT activity in liver was $0.50 \pm 0.03 \mathrm{nmol}$ $\mathrm{min}^{-1} \mathrm{mg}^{-1}$ protein in warm-acclimated fishes and $0.55 \pm 0.04 \mathrm{nmol} \mathrm{min} \mathrm{mg}^{-1}$ protein in coldacclimated fishes $(P>0.05)$. However, GPAT activity was higher in liver compared to pectoral muscle in both cold- and warm-acclimated animals $(P<0.001)$.

\subsection{Expression of genes involved in lipid biosynthesis}

Transcript levels of CDS1 and CDS2 did not change in response to acclimation in liver (Fig. 2A) and were undetectable in pectoral adductor muscle. GPAT1 transcripts increased in liver in animals held at $8{ }^{\circ} \mathrm{C}$ for 1 week and then declined by week 4 , and were equivalent to animals held at $20^{\circ} \mathrm{C}$ (Fig. 2B). AGPAT2 transcript levels did not change in liver during cold acclimation (Fig. 2B). In contrast, AGPAT2 mRNA levels increased in pectoral adductor in animals held at $8{ }^{\circ} \mathrm{C}$ for 1 week and then declined and were equivalent to animals at $20^{\circ} \mathrm{C}$ by week 4 (Fig. 3). GPAT1 mRNA levels did not change in pectoral adductor muscle in response to cold acclimation (Fig. 3) and GPAT2 mRNA was undetectable in liver and oxidative muscle.

\section{Discussion}

Little is known about the molecular mechanisms governing phospholipid biosynthesis during mitochondrial biogenesis but our results indicate that GPAT activity increases in oxidative muscle of stickleback during cold acclimation, coinciding with mitochondrial biogenesis, and may contribute to the synthesis of mitochondrial phospholipids. 
The maximal activity of GPAT significantly increased 2.9-fold in response to cold acclimation in oxidative muscle of stickleback (Fig.1) and was correlated with a 1.9-fold increase in mitochondrial volume density (Orczewska et al., 2010). In contrast, there was no

199 change in GPAT activity in liver (Fig.1) where mitochondrial biogenesis does not occur

200 (Orczewska et al., 2010). These results suggest that GPAT may contribute to mitochondrial membrane biogenesis in oxidative muscle during cold acclimation in stickleback.

GPAT activity was measured at a common temperature of $14{ }^{\circ} \mathrm{C}$. The 2.9 -fold increase in GPAT activity in pectoral adductor muscle in stickleback at $8{ }^{\circ} \mathrm{C}$ compared to those at $20^{\circ} \mathrm{C}$ corresponds with a $\mathrm{Q}_{10}$ of 2.4. The average $\mathrm{Q}_{10}$ for many physiological processes is $\sim 2$, suggesting stickleback have compensated or overcompensated for the effect of temperature on GPAT activity (Hochachka and Somero, 2002). The increase in GPAT activity is on par with the 3.3-fold increase in the activity of superoxide dismutase (SOD), measured in pectoral adductor of stickleback in response to cold acclimation (Kammer et al., 2011). For this study, SOD activity was also measured at the acclimation temperature of the animals $\left(8{ }^{\circ} \mathrm{C}\right.$ and $\left.20^{\circ} \mathrm{C}\right)$ and activity was indeed higher in cold-acclimated animals, indicating overcompensation for thermal effects (Kammer et al., 2011).

The higher maximal activity of GPAT in liver tissue compared to oxidative skeletal

213 muscle is correlated with the higher TAG content of this tissue and likely reflects the dual role of 214 GPAT in synthesizing both phospholipids and TAG (ie; Gimeno and Cao, 2008; Hammond et 215 al., 2002; Igal et al., 2001). TAGs occupy 57 - 59\% of hepatocyte volume compared to only 0.4 $2160.5 \%$ in oxidative pectoral adductor muscle of stickleback (Orczewska et al., 2010). The density 217 of lipid droplets does not change in either pectoral adductor muscle or liver in response to cold 218 acclimation (Orczewska et al., 2010), suggesting that the increase in GPAT activity in pectoral 219 adductor likely contributes to an increase in mitochondrial density in oxidative skeletal muscle 220 rather than increased synthesis of TAGs.

Although GPAT activity increased in response in pectoral muscle after 11 weeks of cold acclimation, GPAT1 mRNA levels did not change and GPAT2 mRNA was undetectable for up

223 to weeks 9 of cold acclimation. These data suggest several possibilities. First, because we did not 224 measure mRNA levels at week 11, we may have missed an increase in transcript levels at this 225 time, although typically increases in mRNA levels precede increases in protein. Alternatively, 
226 the microsomal isoforms of GPAT (GPAT3 and GPAT4) may drive the increase in GPAT 227 activity. In most mammalian tissues, mitochondrial GPATs account for only $10 \%$ of total GPAT 228 activity; the exception is in liver where it accounts for 30-50\% (Coleman and Lee, 2004).

229 Although GPAT3 and GPAT4 are expressed in skeletal muscle (Cao et al., 2008; Chen et al., 230 2008; Shan et al., 2010), we measured mRNA levels of the mitochondrial isoforms because we 231 thought they might be more important in synthesizing phospholipids during mitochondrial 232 biogenesis. In support of this, the mitochondrial isoforms have been shown to alter membrane 233 composition more so than the microsomal isoforms. GPAT1 null mice have altered phospholipid 234 composition in hearts with lower amounts of palmitate in PE, PC and a mixture of PS and PI and 235 higher levels of arachidonate in PC and PE (Lewin et al., 2008). Livers of GPAT1 null mice 236 contain PE and PC with 21\% less palmitate (the preferred fatty acid substrate of GPAT1) at the $237 s n-1$ position and $36 \%$ (in PE) or $40 \%$ (in PC) more arachidonate at the $s n-2$ position (Hammond 238 et al., 2002). Alterations in diet that stimulate TAG synthesis and increase levels of GPAT1 and 239 GPAT3 do not alter mRNA levels of GPAT2, consistent with our original hypothesis that 240 GPAT2 may be more important for the synthesis of phospholipids than TAGs (Wang et al., 241 2007). Other studies however, suggest that microsomal GPATs may also contribute to membrane 242 synthesis. Overexpressing PGC-1 $\alpha$, which stimulates mitochondrial biogenesis, results in 243 remodeling of phospholipids in skeletal muscle and is correlated with increases in both GPAT1 244 and GPAT3 mRNAs (Senoo et al., 2015). Similar to our results, GPAT2 mRNA was not 245 detected in skeletal muscle, nor was GPAT4 in this study (Senoo et al., 2015). Additionally, 246 overexpression of GPAT4 increases levels of PI and alters the abundance of some PC species but 247 does not affect TAG level (Chen et al., 2008; Nagle et al., 2008).

Another possibility for the discordance between mRNA levels of GPAT1 and GPAT2 249 and GPAT activity may be due to phosphorylation of GPAT, which regulates its activity. In rats, 250 a decrease in GPAT activity is correlated with an increase in cAMP kinase activity in liver in 251 response to exercise, although phosphorylation of GPAT was not confirmed in this study (Park et 252 al., 2002). It is thought that under these conditions, a decrease in GPAT activity might divert 253 fatty acyl CoAs to carnitine palmitoyl transferase-1, also localized the outer mitochondrial 254 membrane, for fatty acid oxidation during exercise (Park et al., 2002). Stronger evidence for 255 phosphorylation of GPAT comes from a study in adipocytes, where phosphorylation of GPAT3 
and GPAT4 is required for an insulin-stimulated increase in GPAT activity and is prevented

257 when PI-3 kinase is inhibited (Shan et al., 2010).

While neither GPAT1 nor GPAT2 increased in response to cold acclimation in oxidative muscle, AGPAT2 mRNA levels did. Similarly, AGPAT2 mRNA increased in response to exercise in skeletal muscle of mice, which stimulates mitochondrial biogenesis (Senoo et al., 2015). AGPAT2 is highly expressed in adipose tissue and mutations in AGPAT2 cause congenital generalized lipidodystrophy 1 , characterized by a near complete absence of body fat and impaired insulin signaling (Agarwal et al., 2002). High activity of AGPAT2 is also linked to cancer (Coon et al., 2003). Recently, it has been shown that AGPAT2 regulates mTOR signaling and knocking out AGPAT2 reduces mTOR signaling (Blaskovich et al., 2013). This is interesting because mTOR positively regulates mitochondrial activity (Albert and Hall, 2015), and inhibiting mTOR activity decreases levels of PGC-1 $\alpha$ and NRF-1 and cellular respiration rates in muscle (Cunningham et al., 2007). It is conceivable that the upregulation of AGPAT1 in oxidative muscle of stickleback stimulates mitochondrial biogenesis through an mTOR signaling 270 pathway. muscle both increased after one week of cold acclimation. The two enzymes may work in concert, with G3P being converted to LPA by GPAT1 in liver, which is then exported and taken up by muscle and converted to PA by AGPAT1. Prior studies of cold acclimation in stickleback also found increases in gene expression within the first week of cold acclimation, including citrate synthase in liver and pectoral adductor muscle, and PGC-1 $\beta$ in liver, suggesting metabolic reorganization begins early in the cold acclimation process (Orczewska et al., 2010).

The lack of CDS1 and CDS2 mRNA in pectoral adductor muscle suggest that Tam41, 279 localized to the mitochondrial inner membrane, likely synthesizes CL, as has been shown in 280 yeast (Tamura et al., 2013). Originally, Tam41 was identified as a protein localized to the inner 281 membrane essential for assembling and maintaining the TIM23 complex involved in importing 282 proteins into mitochondria in yeast (Tamura et al., 2006). Later studies showed that knocking out 283 Tam41 virtually eliminated CL and significantly reduced levels of PG, consistent with its 284 function as a CDS (Kutik et al., 2008). 
285 In mice, knocking out PGC-1 $\alpha$ and PGC-1 $\beta$ led to downregulation of CDS1, and a 286 decrease in CL in cardiac myocytes, suggesting contrary to studies in yeast, that CDS1 may be 287 involved in synthesizing CL, although levels of Tam 41 were not measured (Lai et al., 2014). The 288 lack of change in CDS mRNA levels in stickleback, particularly in muscle where mitochondrial 289 biogenesis occurs, may be due to differences in the mitochondrial biogenic pathway between fish 290 and mammals. In contrast to mammals, PGC-1 $\alpha$ is not the master regulator of mitochondrial 291 biogenesis in fish. PGC-1 $\alpha$ levels do not change in response to cold acclimation in muscle of 292 goldfish (Bremer et al., 2012; LeMoine et al., 2008), zebrafish (McClelland et al., 2006) or 293 stickleback (Orczewska et al., 2010), nor in response to exercise in zebrafish (McClelland et al., 294 2006). Comparison of PGC-1 $\alpha$ sequences among vertebrates revealed a polyserine insertion 295 within the NRF-1 binding domain of PGC-1 $\alpha$ in teleosts, which may eliminate its capacity to 296 mediate mitochondrial biogenesis (LeMoine et al., 2008). Indeed, NRF-1 and PGC-1 $\beta$ appear to 297 play a more prominent role in inducing mitochondrial biogenesis in fish (Bremer et al., 2012; 298 LeMoine et al., 2008; McClelland et al., 2006). Future studies might investigate the role of NRF2991 and PGC-1 $\beta$ in regulating the transcription of GPAT and AGPAT isoforms to further elucidate 300 how mitochondrial phospholipid biosynthesis is integrated into mitochondrial biogenesis in fish.

\section{Acknowledgements}

303 Funding for this research was provided by a grant from the National Science Foundation to 304 K.M.O. (IOS-0643857). 


\section{FIGURE LEGENDS}

Figure 1. GPAT activity in liver and oxidative muscle of stickleback held at $8{ }^{\circ} \mathrm{C}$ and $20{ }^{\circ} \mathrm{C}$. Significant differences are indicated with asterisks $(P<0.05)$. Values represent the means \pm s.e.m. $N=6$.

Figure 2. Relative transcript levels of genes involved in membrane biosynthesis in liver. Relative transcript levels of (A) CDS1 and CDS2 and (B) GPAT1 and AGAT2 measured in stickleback liver during cold and warm acclimation. Transcript levels were normalized to $18 \mathrm{~S}$ mRNA. Different letters indicate significant differences among fish harvested at different times and temperatures during acclimation $(P<0.05) . N=6-8$.

Figure 3. Relative transcript levels of genes involved in membrane biosynthesis in oxidative skeletal muscle. Relative transcript levels of GPAT1 and AGPAT2 were measured in pectoral adductor muscle of stickleback during cold and warm acclimation. Transcript levels were normalized to EF-1 $\alpha$. Different letters indicate significant differences among fish harvested at different times and temperatures during acclimation $(P<0.05) . N=6-8$. 


\section{Table 1.}

Primers used for qRT-PCR

\begin{tabular}{|c|c|c|c|}
\hline Gene & Sequence (5' to 3') & $\begin{array}{l}\text { Primer } \\
\text { Efficiency }\end{array}$ & $\begin{array}{l}\text { Amplicon } \\
\text { Size (bp) }\end{array}$ \\
\hline \multirow{2}{*}{$\begin{array}{c}\text { AGPAT2 } \\
\text { ENSGACG00000015898 }\end{array}$} & F ATCATCTCCAACCACCAGAGCT & \multirow{2}{*}{$0.93 \pm 0.05$} & \multirow{2}{*}{51} \\
\hline & R GATCTCCATCAGGCCCAACA & & \\
\hline \multirow{2}{*}{$\begin{array}{c}\text { CDS1 } \\
\text { ENSGACG00000014333 }\end{array}$} & F CAGTTCCTGGCGCGCTAT & \multirow{2}{*}{$0.95 \pm 0.04$} & \multirow{2}{*}{51} \\
\hline & R TGCGAGGTACAAGGCGAAG & & \\
\hline \multirow{2}{*}{$\begin{array}{c}\text { CDS2 } \\
\text { ENSGACG00000013234 }\end{array}$} & F CTCTTCGCATCCTCAGCAAATAC & \multirow{2}{*}{$0.89 \pm 0.03$} & \multirow{2}{*}{51} \\
\hline & R GGTAGAGGGCAAAGGAGATGAAT & & \\
\hline \multirow{2}{*}{$\begin{array}{c}\text { GPAT1 } \\
\text { ENSGACG00000006114 }\end{array}$} & F ACAGCAATGGCCTTTTCCAC & \multirow{2}{*}{$0.86 \pm 0.02$} & \multirow{2}{*}{51} \\
\hline & R TGCAAGCAATGATTGCATCAG & & \\
\hline \multirow{2}{*}{$\begin{array}{c}\text { GPAT2 } \\
\text { ENSGACG00000005887 }\end{array}$} & F CCCGGATAGAAGCGTGAGG & \multirow{2}{*}{$0.75 \pm 0.11$} & \multirow{2}{*}{51} \\
\hline & R TCCTTGAGAGAAAAGGGCTGAG & & \\
\hline
\end{tabular}

Ensembl accession numbers are shown below each gene; $\mathrm{F}=$ forward primer, $\mathrm{R}=$ reverse primer 
Table 2. Effects of cold temperature on physical characteristics of G. aculeatus used for measuring GPAT activity.

\begin{tabular}{cccc}
\hline Temperature & $\mathbf{N}$ & Length $(\mathbf{c m})$ & Body Mass (g) \\
\hline $8{ }^{\circ} \mathrm{C}$ & 12 & $5.59 \pm 0.14$ & $1.53 \pm 0.08$ \\
$20^{\circ} \mathrm{C}$ & 12 & $5.77 \pm 0.12$ & $1.65 \pm 0.08$ \\
\hline
\end{tabular}

Values are means \pm s.e.m. $N=$ number of individuals 
Table 3. Effects of cold temperature on physical characteristics of $G$. aculeatus used for measuring mRNA levels of genes involved in phospholipid biosynthesis.

\begin{tabular}{lccc}
\hline $\begin{array}{c}\text { Temperature and } \\
\text { Time Point of } \\
\text { Harvest }\end{array}$ & $\boldsymbol{N}$ & Length (cm) & Body Mass (g) \\
\hline $8{ }^{\circ} \mathrm{C}$ week 1 & 16 & $4.94 \pm 0.06$ & $1.24 \pm 0.06$ \\
$8{ }^{\circ} \mathrm{C}$ week 4 & 11 & $5.14 \pm 0.13$ & $1.44 \pm 0.11$ \\
$8{ }^{\circ} \mathrm{C}$ week 9 & 9 & $5.41 \pm 0.07$ & $1.60 \pm 0.08$ \\
$20{ }^{\circ} \mathrm{C}$ week 1 & 10 & $5.18 \pm 0.13$ & $1.41 \pm 0.10$ \\
$20{ }^{\circ} \mathrm{C}$ week 9 & 10 & $5.45 \pm 0.10$ & $1.59 \pm 0.10$ \\
\hline
\end{tabular}

Values are means \pm s.e.m. $N=$ number of individuals 


\section{References}

Agarwal, A.K., Arioglu, E., De Almeida, S., Akkoc, N., Taylor, S.I., Bowcock, A.M., Barnes, R.I., Garg, A., 2002. AGPAT2 is mutated in congenital generalized lipodystrophy linked to chromosome 9q34. Nat. Genet. 31, 21-23.

Albert, V., Hall, M.N., 2015. mTOR signaling in cellular and organismal energetics. Curr. Opin. Cell. Biol. 33, 55-66.

Bell, R.M., Coleman, R.A., 1980. Enzymes of glycerolipid synthesis in eukaryotes. Annu. Rev. Biochem. 49, 459-487.

Blaskovich, M.A., Yendluri, V., Lawrence, H.R., Lawrence, N.J., Sebti, S.M., Springett, G.M., 2013. Lysophosphatidic acid acyltransferase beta regulates mTOR signaling. PLoS One 8, e78632.

Bradford, M.M., 1976. A rapid and sensitive method for the quantitation of microgram quantities of protein utilizing the principle of protein-dye binding. Anal. Biochem. 72, 248-254.

Bremer, K., Kocha, K.M., Snider, T., Moyes, C.D., 2015. Sensing and responding to energetic stress: The role of the AMPK-PGC1alpha-NRF1 axis in control of mitochondrial biogenesis in fish. Comp. Biochem. Physiol. B.

Bremer, K., Monk, C.T., Gurd, B.J., Moyes, C.D., 2012. Transcriptional regulation of temperature-induced remodeling of muscle bioenergetics in goldfish. Am. J. Physiol. 303, R150158.

Cao, J., Shan, D., Revett, T., Li, D., Wu, L., Liu, W., Tobin, J.F., Gimeno, R.E., 2008. Molecular identification of a novel mammalian brain isoform of acyl-CoA:lysophospholipid acyltransferase with prominent ethanolamine lysophospholipid acylating activity, LPEAT2. J. Biol. Chem. 283, 19049-19057. 
Chen, Y.Q., Kuo, M.S., Li, S., Bui, H.H., Peake, D.A., Sanders, P.E., Thibodeaux, S.J., Chu, S., Qian, Y.W., Zhao, Y., Bredt, D.S., Moller, D.E., Konrad, R.J., Beigneux, A.P., Young, S.G., Cao, G., 2008. AGPAT6 is a novel microsomal glycerol-3-phosphate acyltransferase. J. Biol. Chem. 283, 10048-10057.

Coleman, R.A., Lee, D.P., 2004. Enzymes of triacylglycerol synthesis and their regulation. Prog. Lipid Res. 43, 134-176.

Coon, M., Ball, A., Pound, J., Ap, S., Hollenback, D., White, T., Tulinsky, J., Bonham, L., Morrison, D.K., Finney, R., Singer, J.W., 2003. Inhibition of lysophosphatidic acid acyltransferase beta disrupts proliferative and survival signals in normal cells and induces apoptosis of tumor cells. Mol. Cancer Ther. 2, 1067-1078.

Cunningham, J.T., Rodgers, J.T., Arlow, D.H., Vazquez, F., Mootha, V.K., Puigserver, P., 2007. mTOR controls mitochondrial oxidative function through a YY1-PGC-1alpha transcriptional complex. Nature 450, 736-740.

D'Souza, K., Kim, Y.J., Balla, T., Epand, R.M., 2014. Distinct properties of the two isoforms of CDP-diacylglycerol synthase. Biochem. 53, 7358-7367.

Egginton, S., Sidell, B.D., 1989. Thermal acclimation induces adaptive changes in subcellular structure of fish skeletal muscle. Am. J. Physiol. 256, R1-9.

Gimeno, R.E., Cao, J., 2008. Thematic review series: glycerolipids. Mammalian glycerol-3phosphate acyltransferases: new genes for an old activity. J. Lipid Res. 49, 2079-2088.

Hammond, L.E., Gallagher, P.A., Wang, S., Hiller, S., Kluckman, K.D., Posey-Marcos, E.L., Maeda, N., Coleman, R.A., 2002. Mitochondrial glycerol-3-phosphate acyltransferase-deficient mice have reduced weight and liver triacylglycerol content and altered glycerolipid fatty acid composition. Mol. Cell Biol. 22, 8204-8214. 
Hochachka, P.W., Somero, G.N., 2002. Biochemical Adaptation: Mechanism and process in physiological evolution. Oxford University Press, Oxford.

Horvath, S.E., Daum, G., 2013. Lipids of mitochondria. Progress in lipid research 52, 590-614. Igal, R.A., Wang, S., Gonzalez-Baro, M., Coleman, R.A., 2001. Mitochondrial glycerol phosphate acyltransferase directs the incorporation of exogenous fatty acids into triacylglycerol. J. Biol. Chem. 276, 42205-42212.

Johnston, I.A., Maitland, B., 1980. Temperature acclimation in crucian carp, Carassius carassius L., morphometric analyses of muscle fibre ultrastructure. J. Fish Biol. 17, 113-125.

Kammer, A.R., Orczewska, J.I., O'Brien, K.M., 2011. Oxidative stress is transient and tissue specific during cold acclimation of threespine stickleback. J Exp Biol 214, 1248-1256.

Kutik, S., Rissler, M., Guan, X.L., Guiard, B., Shui, G., Gebert, N., Heacock, P.N., Rehling, P., Dowhan, W., Wenk, M.R., Pfanner, N., Wiedemann, N., 2008. The translocator maintenance protein Tam41 is required for mitochondrial cardiolipin biosynthesis. J. Cell Biol. 183, 12131221.

Lai, L., Wang, M., Martin, O.J., Leone, T.C., Vega, R.B., Han, X., Kelly, D.P., 2014. A role for peroxisome proliferator-activated receptor gamma coactivator 1 (PGC-1) in the regulation of cardiac mitochondrial phospholipid biosynthesis. J. Biol. Chem. 289, 2250-2259.

LeMoine, C.M., Genge, C.E., Moyes, C.D., 2008. Role of the PGC-1 family in the metabolic adaptation of goldfish to diet and temperature. J. Exp. Biol. 211, 1448-1455.

Lewin, T.M., de Jong, H., Schwerbrock, N.J., Hammond, L.E., Watkins, S.M., Combs, T.P., Coleman, R.A., 2008. Mice deficient in mitochondrial glycerol-3-phosphate acyltransferase-1 have diminished myocardial triacylglycerol accumulation during lipogenic diet and altered phospholipid fatty acid composition. Biochim. Biophys. Acta 1781, 352-358. 
McClelland, G.B., Craig, P.M., Dhekney, K., Dipardo, S., 2006. Temperature- and exerciseinduced gene expression and metabolic enzyme changes in skeletal muscle of adult zebrafish (Danio rerio). J. Physiol. 577, 739-751.

Nagle, C.A., Vergnes, L., Dejong, H., Wang, S., Lewin, T.M., Reue, K., Coleman, R.A., 2008. Identification of a novel sn-glycerol-3-phosphate acyltransferase isoform, GPAT4, as the enzyme deficient in Agpat6-/- mice. J. Lipid Res. 49, 823-831.

O'Brien, K.M., Mueller, I.A., 2010. The unique mitochondrial form and function of Antarctic channichthyid icefishes. Integr. Comp. Biol. 50, 993-1008.

Orczewska, J.I., Hartleben, G., O'Brien, K.M., 2010. The molecular basis of aerobic metabolic remodeling differs between oxidative muscle and liver of threespine sticklebacks in response to cold acclimation. Am. J. Physiol. 299, R352-364.

Park, H., Kaushik, V.K., Constant, S., Prentki, M., Przybytkowski, E., Ruderman, N.B., Saha, A.K., 2002. Coordinate regulation of malonyl-CoA decarboxylase, sn-glycerol-3-phosphate acyltransferase, and acetyl-CoA carboxylase by AMP-activated protein kinase in rat tissues in response to exercise. J. Biol. Chem. 277, 32571-32577.

Ren, M., Phoon, C.K., Schlame, M., 2014. Metabolism and function of mitochondrial cardiolipin. Prog. Lipid Res. 55, 1-16.

Scarpulla, R.C., 2008. Nuclear control of respiratory chain expression by nuclear respiratory factors and PGC-1-related coactivator. Ann. NY Acad. Sci. 1147, 321-334.

Senoo, N., Miyoshi, N., Goto-Inoue, N., Minami, K., Yoshimura, R., Morita, A., Sawada, N., Matsuda, J., Ogawa, Y., Setou, M., Kamei, Y., Miura, S., 2015. PGC-1alpha-mediated changes in phospholipid profiles of exercise-trained skeletal muscle. J. Lipid Res. 56, 2286-2296. 
Shan, D., Li, J.L., Wu, L., Li, D., Hurov, J., Tobin, J.F., Gimeno, R.E., Cao, J., 2010. GPAT3 and GPAT4 are regulated by insulin-stimulated phosphorylation and play distinct roles in adipogenesis. J. Lipid Res. 51, 1971-1981.

Takeuchi, K., Reue, K., 2009. Biochemistry, physiology, and genetics of GPAT, AGPAT, and lipin enzymes in triglyceride synthesis. Am. J. Physiol. Endocrinol. Metab. 296, E1195-1209.

Tamura, Y., Harada, Y., Nishikawa, S., Yamano, K., Kamiya, M., Shiota, T., Kuroda, T., Kuge, O., Sesaki, H., Imai, K., Tomii, K., Endo, T., 2013. Tam41 is a CDP-diacylglycerol synthase required for cardiolipin biosynthesis in mitochondria. Cell Metab. 17, 709-718.

Tamura, Y., Harada, Y., Yamano, K., Watanabe, K., Ishikawa, D., Ohshima, C., Nishikawa, S., Yamamoto, H., Endo, T., 2006. Identification of Tam41 maintaining integrity of the TIM23 protein translocator complex in mitochondria. J. Cell Biol. 174, 631-637.

Tyler, S., Sidell, B., 1984. Changes in mitochondrial distribution and diffusion distances in muscle of goldfish upon acclimation to warm and cold temperatures. J. Exp. Zool. 232, 1-9.

Vancura, A., Haldar, D., 1994. Purification and characterization of glycerophosphate acyltransferase from rat liver mitochondria. J. Biol. Chem. 269, 27209-27215.

Wang, S., Lee, D.P., Gong, N., Schwerbrock, N.M., Mashek, D.G., Gonzalez-Baro, M.R., Stapleton, C., Li, L.O., Lewin, T.M., Coleman, R.A., 2007. Cloning and functional characterization of a novel mitochondrial N-ethylmaleimide-sensitive glycerol-3-phosphate acyltransferase (GPAT2). Arch. Biochem. Biophys. 465, 347-358.

Wendel, A.A., Lewin, T.M., Coleman, R.A., 2009. Glycerol-3-phosphate acyltransferases: rate limiting enzymes of triacylglycerol biosynthesis. Biochim. Biophys. Acta 1791, 501-506. 
Figure 1

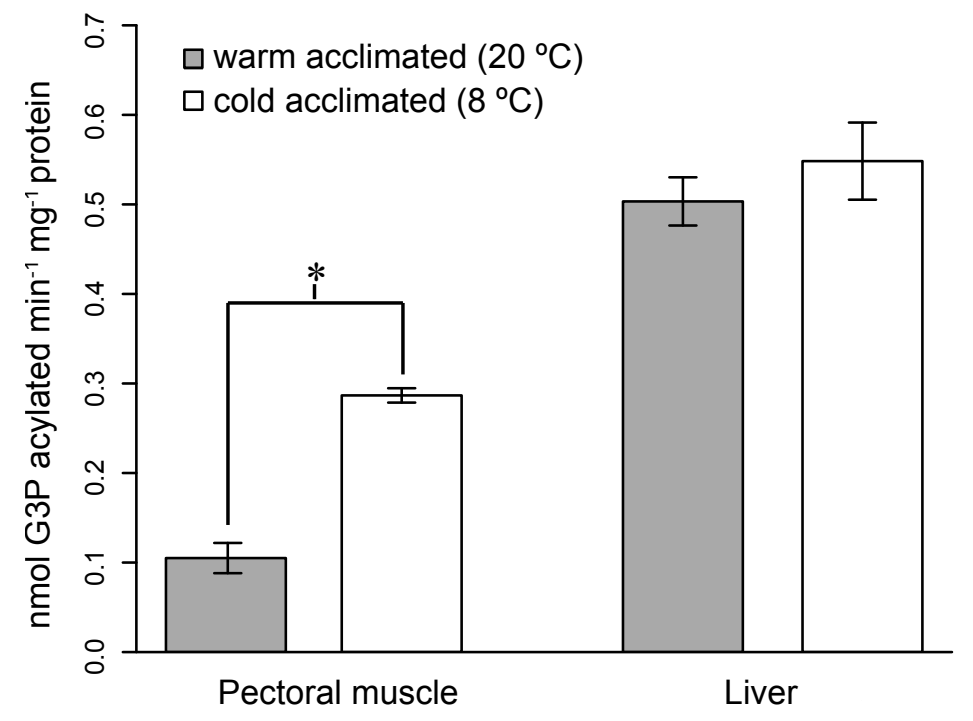


Figure 2
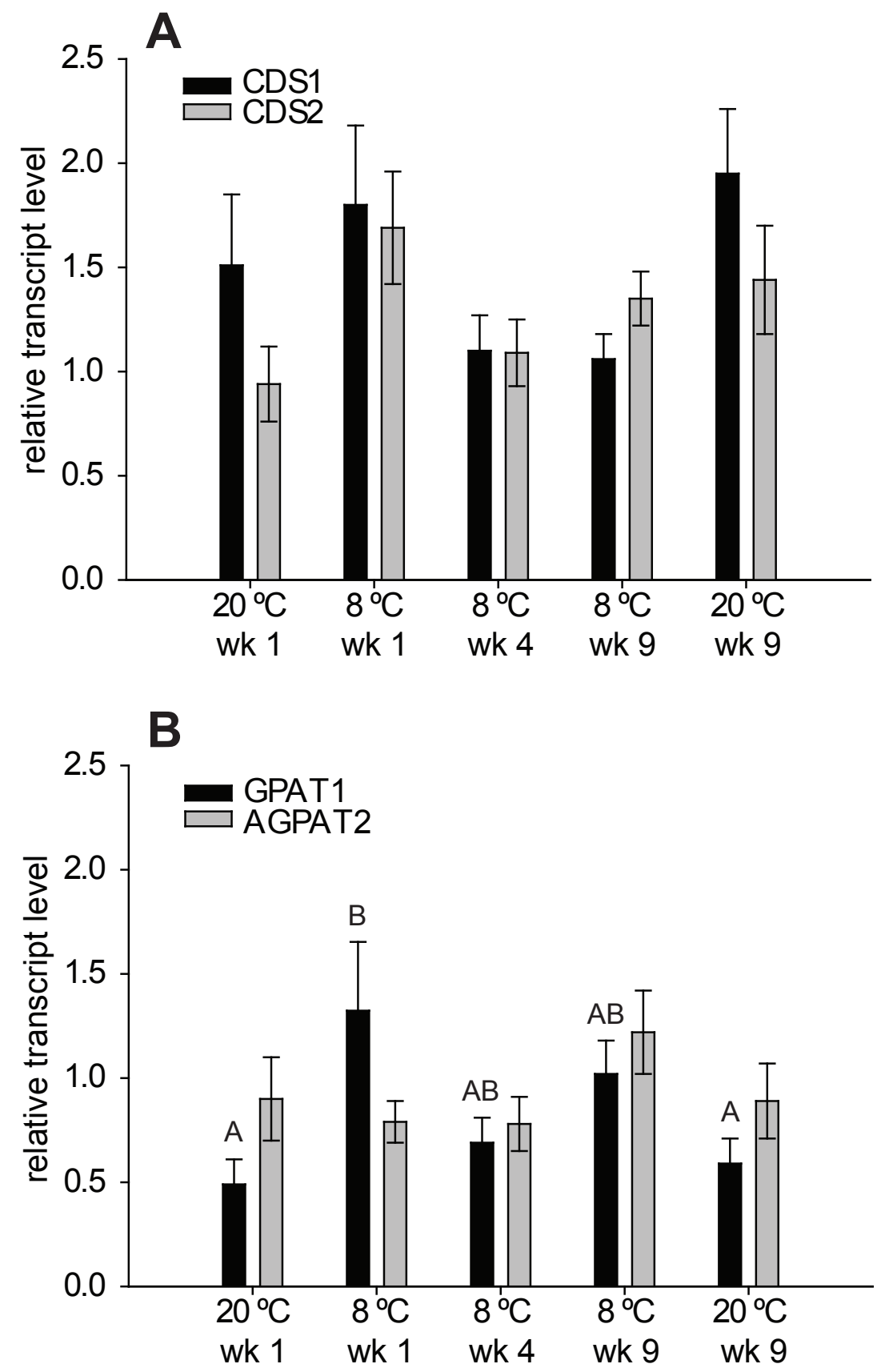
Figure 3

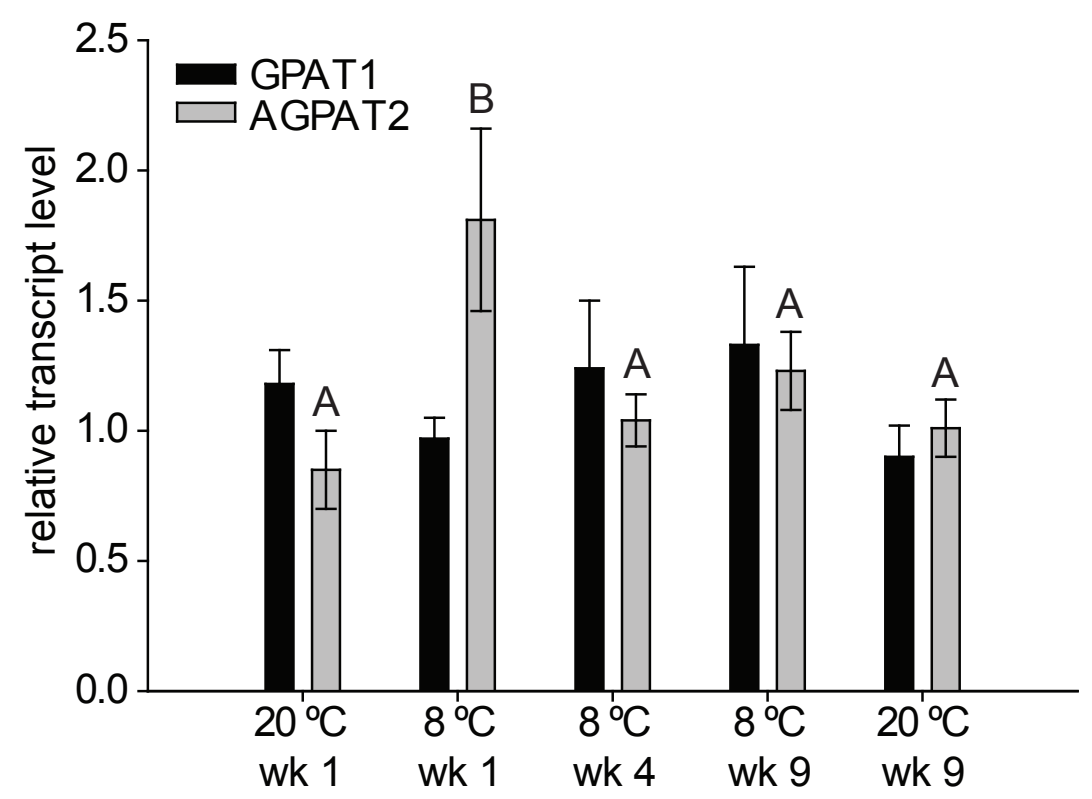

